\title{
EGFR NP_005219.2:p.L718X
}

National Cancer Institute

\section{Source}

National Cancer Institute. EGFR NP 005219.2:p.L718X. NCI Thesaurus. Code C147133.

A change in the amino acid residue at position 718 in the epidermal growth factor receptor protein where leucine has been replaced by another amino acid. 